\title{
Increased arginase II activity contributes to endothelial dysfunction through endothelial nitric oxide synthase uncoupling in aged mice
}

\author{
Woosung Shin ${ }^{1}$, Dan E. Berkowitz ${ }^{2,3}$ \\ and Sungwoo Ryoo ${ }^{1,4}$ \\ ${ }^{1}$ Department of Biology \\ College of Natural Sciences \\ Kangwon National University \\ Chuncheon 200-701, Korea \\ ${ }^{2}$ Department of Anesthesiology and Critical Care Medicine \\ ${ }^{3}$ Department of Biomedical Engineering \\ Johns Hopkins Medical Institutions \\ Baltimore, MD 21287, USA \\ ${ }^{4}$ Corresponding author: Tel, 82-33-250-8534; \\ Fax, 82-33-251-3990; E-mail, ryoosw08@ kangwon.ac.kr \\ http://dx.doi.org/10.3858/emm.2012.44.10.068
}

Accepted 27 July 2012

Available Online 2 August 2012

Abbreviations: $\mathrm{ABH}, 2$ (S)-amino-6-boronohexanoic acid; Ach, acetylcholine; Arg I, arginase I; Argll, arginase II; DAF, 4-amino5-methylamino-2', 7'-difluorescein; DHE, dihydroethidium; L-arg, L-arginine; L-NAME, L-N ${ }^{G}$-nitroarginine methyl ester; MnTBAP, Mn (III)tetrakis (4-benzoic acid) porphyrin chloride; ns, not significant; ROS, reactive oxygen species; siArgll, siRNA to arginase II

\begin{abstract}
The incidence of cardiovascular disease is predicted to increase as the population ages. There is accumulating evidence that arginase upregulation is associated with impaired endothelial function. Here, we demonstrate that arginase II (Argll) is upregulated in aortic vessels of aged mice and contributes to decreased nitric oxide (NO) generation and increased reactive oxygen species (ROS) production via endothelial nitric oxide synthase (eNOS) uncoupling. Inhibiting Argll with small interfering RNA technique restored eNOS coupling to that observed in young mice and increased NO generation and decreased ROS production. Furthermore, enhanced vasoconstrictor responses to U46619 and attenuated vasorelaxation responses to acetylcholine in aged vasculature were markedly improved following siRNA treatment against
\end{abstract}

Argll. These results might be associated with increased L-arginine bioavailability. Collectively, these results suggest that Argll may be a valuable target in age-dependent vascular diseases.

Keywords: aging; arginase II; endothelial nitric oxide synthase uncoupling; small interfering RNA; vascular diseases

\section{Introduction}

Cardiovascular disease is the leading cause of morbidity and mortality in both industrialized and developing countries. Despite effective treatments for several established cardiovascular risk factors, such as hypertension and hypercholesterolemia, the incidence of cardiovascular disease is predicted to increases as the population ages. Characteristic events in the aging cardiovascular system include vascular stiffness (Meaume et al., 2001), enhanced reactive oxygen species (ROS) production (Finkel and Holbrook, 2000; Brandes et al., 2005), and decreased nitric oxide (NO) bioavailability (Adler et al., 2003; Csiszar et al., 2008). Superoxide may react with $\mathrm{NO}$ to produce peroxynitrite $\left(\mathrm{ONOO}^{-}\right)$, which is potentially detrimental to vascular cell function and viability. This nitroso-redox imbalance contributes to age- related endothelial dysfunction and vascular stiffness (Berkowitz et al., 2003).

Arginase is well demonstrated as an important enzyme in the last step of the urea cycle, which hydrolyzes L-arginine to L-ornithine and urea. There are two isoforms: arginase I (Argl), also known as the hepatic isoform, and arginase II (Argll), which is an extrahepatic enzyme. These proteins are encoded by different genes (Haraguchi et al., 1987; Morris et al., 1997) and are induced by a variety of factors (Meurs et al., 2003). Arginase isoforms are found in a wide variety of cells and tissues, and current reports suggest that they may be expressed in species- and tissue-specific manners (Abe and Berk, 1998; Morris et al., 1998; Chicoine et al., 2004; Ryoo et al., 2006; Nelin et al., 2007). There is increasing evidence that arginase upregulation 
functionally inhibits nitric oxide synthase (NOS) activity and contributes to age-related vascular dysfunction (Berkowitz et al., 2003; Ryoo et al., 2006). Pharmacological inhibition and antisense knockdown of Argl restores endothelial NO production and endothelial function ex vivo (Ryoo et al., 2006). Arginase-mediated reciprocal regulation of NOS has been demonstrated in the majority of cell types and organs in which $\mathrm{NO}$ is an important signaling molecule, including cardiomyocytes (Steppan et al., 2006), the penis (Bivalacqua et al., 2007), the airway (Meurs et al., 2003), skin (Holowatz and Kenney, 2007), inflammatory mediator cells (e.g., macrophages), and endothelial cells (Berkowitz et al., 2003).

Although vascular changes associated with aging have been investigated in humans and a number of other species, it is thought that the relative contributions of dysregulated mechanisms to agerelated vascular pathology are species-dependent (Santhanam et al., 2008). Moreover, the contribution of vascular control mechanisms in health, aging, and disease conditions is influenced by regional vascular beds and vessel type and size (Santhanam et al., 2008). Therefore, we investigated which arginase isoform contributes to age-related endothelial dysfunction in mice and determined whether specific inhibition of arginase isoforms with small interfering RNA (siRNA) was able to restore vascular function. We also analyzed L-arginine (L-arg) concentrations in isolated aortic vessels to elucidate the underlying mechanism of endothelial nitric oxide synthase (eNOS) activation.

\section{Results}

\section{Argll is the key isoform regulating arginase activity in the aorta of aged mice}

We first analyzed arginase expression in young and aged groups (Figures 1A and 1B). Argll was strongly expressed, but we did not detect Argl. Neither the expression level of Argll protein (A, young vs. aged, $1.0 \pm 0.07$ vs. $1.05 \pm 0.06$, ns) nor mRNA (B, young vs. aged, $1.0 \pm 0.08$ vs. $1.01 \pm 0.04$, ns) was significantly different between groups. Next, we measured arginase activity with or without preincubation of siRNAs to specific arginase isoforms (siArgl and siArgll). siArgll incubation with young aortic vessels resulted in decrease of arginase activity (Figure 1C, ${ }^{\text {\# }}$ vs. young, $88.6 \pm 3.0$ vs. $100.0 \pm 7.1, P<0.05$ ) that was associated with decreased protein levels (Figure 1D, " vs. young, $0.81 \pm 0.07$ vs. $1.0 \pm 0.01, P<0.05$ ). Furthermore, increased arginase activity in the aged group (Figure $1 \mathrm{C},{ }^{*}$ vs. young, $137.52 \pm 6.1$ vs. $100.0 \pm 7.1, P<$
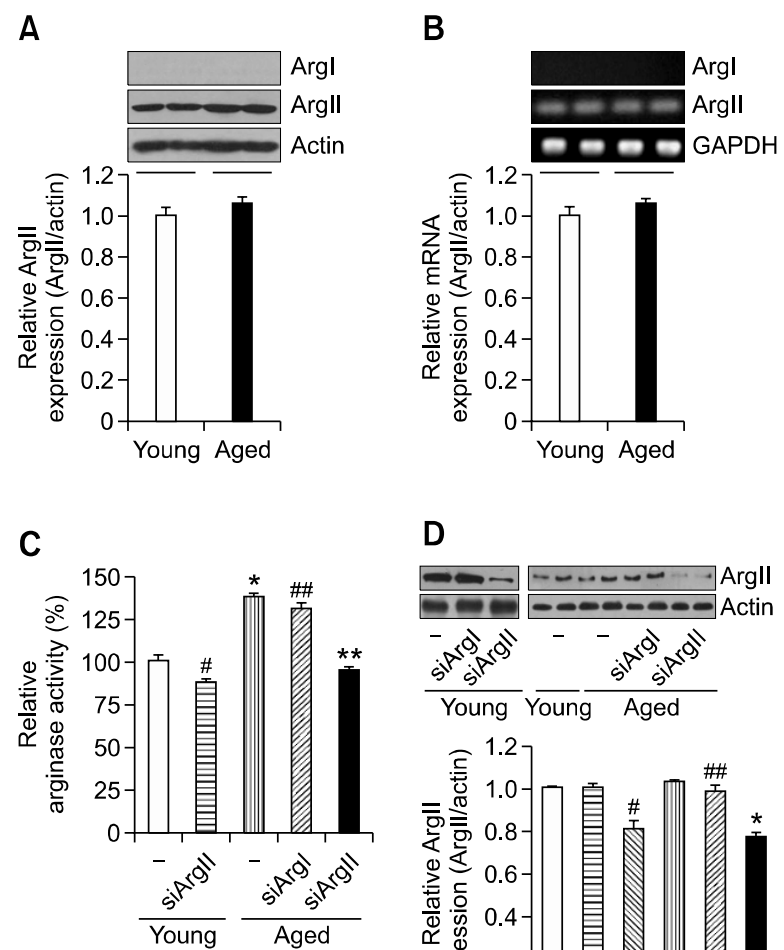

D

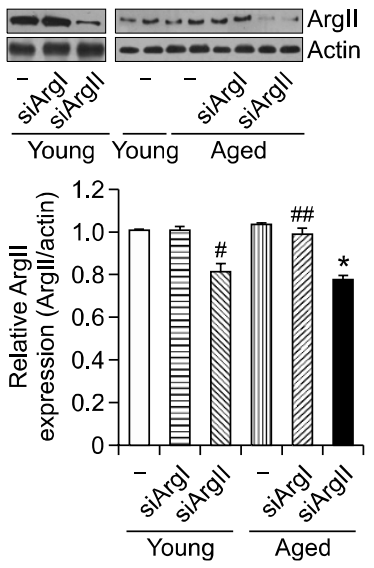

Figure 1. Upregulation of Argll activity in aged mice aortas. (A) Western blot analysis of aortas from young and aged mice. Similar levels of Argll were found in both groups, but Argl protein was not detectable (upper). The lower panel shows the densitometric analysis, $n=4$ experiments. (B) Argl and Argll mRNA expression levels were analyzed by RT-PCR using GAPDH as a control. Only Argll mRNA was detected (upper). The lower panel shows the densitometric analysis, $n=4$ experiments. (C) siArgll incubation decreased arginase activity in both young and aged aortas ( ${ }^{\#}$ vs. young, $P<0.05 ;{ }^{*}$ vs. young, $P<0.01 ;{ }^{* *}$ vs. aged, $P<$ 0.01). (D) siArgll effectively downregulated Argll protein expression in both young and old aortas ( ${ }^{\#}$ vs. young, $P<0.05$; ${ }^{*}$ vs. aged, $P<$ 0.01), but not with siArgl ("\# vs. aged, ns).

0.01 ) was markedly attenuated by siArgll (Figure 1C, ** vs. aged, $137.52 \pm 6.1$ vs. $94.8 \pm 3.2 \%, P<$ 0.01 ) that resulted from downregulated Argll protein levels (Figure $1 \mathrm{D},{ }^{*}$ vs. aged, $0.77 \pm 0.04$ vs. $1.0 \pm$ $0.01, P<0.01)$. However, siArgl had no effect on either protein level or enzyme activity. (Figures 1C and $1 \mathrm{D},{ }^{\#}$ vs. aged, ns). These results imply that the Argll isoform was the dominantly expressed enzyme in the vasculature of aged mice.

\section{eNOS uncoupling in aged aorta was restored with siArgll}

We next assessed eNOS expression in both groups. Interestingly, eNOS protein expression was significantly 
A

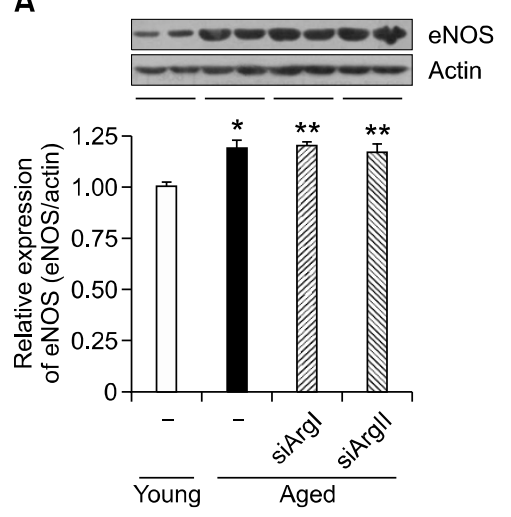

B

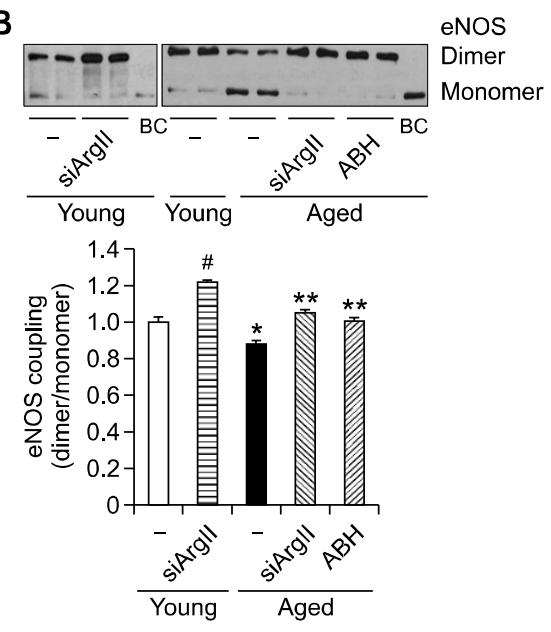

Figure 2. Increased Argll activity was associated with eNOS uncoupling. (A) Increased eNOS expression in aged aorta was not attenuated by siArgll (* vs. young, $P<0.01$; ** vs. aged, ns). (B) siArgll incubation induced eNOS coupling in young aorta ( ${ }^{\#}$ vs. young, $P<0.01)$. Augmented eNOS uncoupling in aged aorta was decreased by siArgll. Incubation of aged aorta with the arginase inhibitor, $\mathrm{ABH}(10 \mu \mathrm{M})$, enhanced eNOS dimerization ( ${ }^{*}$ vs. young, $P$ $0.01 ;{ }^{* *}$ vs. aged, $P<0.01$ ). Densitometric analysis of Western blot (lower panel). increased in the aged group (* vs. young, $1.18 \pm$ 0.05 vs. $1.00 \pm 0.02, P<0.01)$. This observation was not affected by incubation with siArgl or siArgll (Figure 2A, ${ }^{* *}$ vs. aged, ns). Therefore, we tested whether eNOS expression levels were associated with its activity by measuring eNOS dimers and found that the dimer to monomer ratio was markedly reduced in the aged group (Figure $2 \mathrm{~B}$, * vs. young, $0.87 \pm 0.02$ vs. $1.00 \pm 0.02, \quad P<0.05)$. The decreased ratio of eNOS dimer/monomer was recovered by inhibition of arginase activity using either siRNA (** vs. aged, $1.04 \pm 0.02$ vs. $0.87 \pm$ $0.02, P<0.05$ ) or a known arginase inhibitor, $\mathrm{ABH}$ (** vs. aged, $1.00 \pm 0.02$ vs. $0.87 \pm 0.02, P<$ $0.05)$. The effect of siArgll on eNOS coupling was also found in young aorta ( ${ }^{*}$ vs. young, $1.21 \pm 0.02$ vs. $1.00 \pm 0.02, P<0.05$ ). These results suggest that endothelial function in aged mice is impaired despite increased eNOS expression.

\section{siArgll affected NO production and ROS generation in aged mice}

Based on the eNOS coupling data, we next measured NO production and ROS generation in endothelium from young and aged mice. As demonstrated in Figure $3 \mathrm{~A}, \mathrm{NO}$ production was significantly attenuated in aged mice ( ${ }^{*}$ vs. young, $0.58 \pm 0.16$ vs. $0.90 \pm$ 0.19 change of DAF fluorescence/second, $P<$ 0.01). It was restored following siArgll and $A B H$ treatment ${ }^{* *}$ siArgll vs. aged, $0.87 \pm 0.11$ vs. 0.58 $\pm 0.16, P<0.01 ;{ }^{* *} \mathrm{ABH}$ vs. aged, $0.81 \pm 0.14 \mathrm{vs}$. $0.58 \pm 0.16$ change of DAF fluorescence/second, $P$ $<0.01$ ), but siArgl had no effect. Consistent with the data, siArgll induced increase in the slope of DAF fluorescence in young mice $\left({ }^{\#}\right.$ vs. young, 1.13 \pm 0.10 vs. $0.90 \pm 0.19$ change of DAF fluorescence/ second, $P<0.05)$. On the other hand, ROS generation
A

B
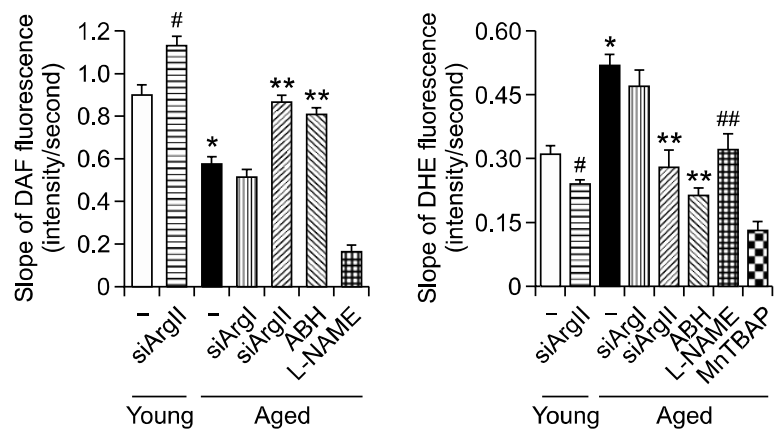

Figure 3. Inhibition of Argll activity restored impaired endothelial function in aged mice. Isolated aortic segments were incubated with DAF-AM (5 $\mu \mathrm{M}$ ) and fluorescence was measured in real-time (endothelium side up). The slope of DAF fluorescence was determined. (A) siArgll incubation with young vessels increased the slope of DAF fluorescence ( ${ }^{*}$ vs. young, $P<0.01$ ). However, DAF fluorescence was decreased in aged mouse aorta and increased following siArgll (but not siArgl) and $A B H$ incubation. L-NAME was used as a control ( ${ }^{*}$ vs. young, $P<0.01$; ** vs. aged, $P<0.01 ; n=4$ mice). (B) ROS production in aortic endothelium was measured with DHE $(5 \mu \mathrm{M})$, and the slope of DHE fluorescence was determined using cumulative data. Arginase inhibition with siArgll and $\mathrm{ABH}$ reciprocally regulated $\mathrm{ROS}$ production $\left({ }^{\#}\right.$ vs. young, $P<0.01$; * vs. young, $P<0.01$; ${ }^{* *}$ vs. aged, $P<0.01 ;{ }^{\# *}$ vs. aged, $P<0.01 ; n=4$ mice). MnTBAP was used as a control.

was markedly augmented in aged mice (Figure 3B, * vs. young, $0.52 \pm 0.04$ vs. $0.31 \pm 0.03$ change of DHE fluorescence/second, $P<0.01$ ), but this was reduced to the level of young endothelium after siArgll and $\mathrm{ABH}$ incubation ${ }^{* *}$, siArgll vs. aged, 0.28 \pm 0.07 vs. $0.52 \pm 0.04, P<0.01$; **, $\mathrm{ABH}$ vs. aged, $0.21 \pm 0.06$ vs. $0.52 \pm 0.04$ change of DHE fluorescence/second, $P<0.01$ ). siArgll incubation also reduced ROS generation in young mice $\left({ }^{\#}\right.$ vs. young, $0.24 \pm 0.04$ vs. $0.31 \pm 0.03$ change of $D H E$ fluorescence/second, $P<0.05$ ). Interestingly, L-NG- 

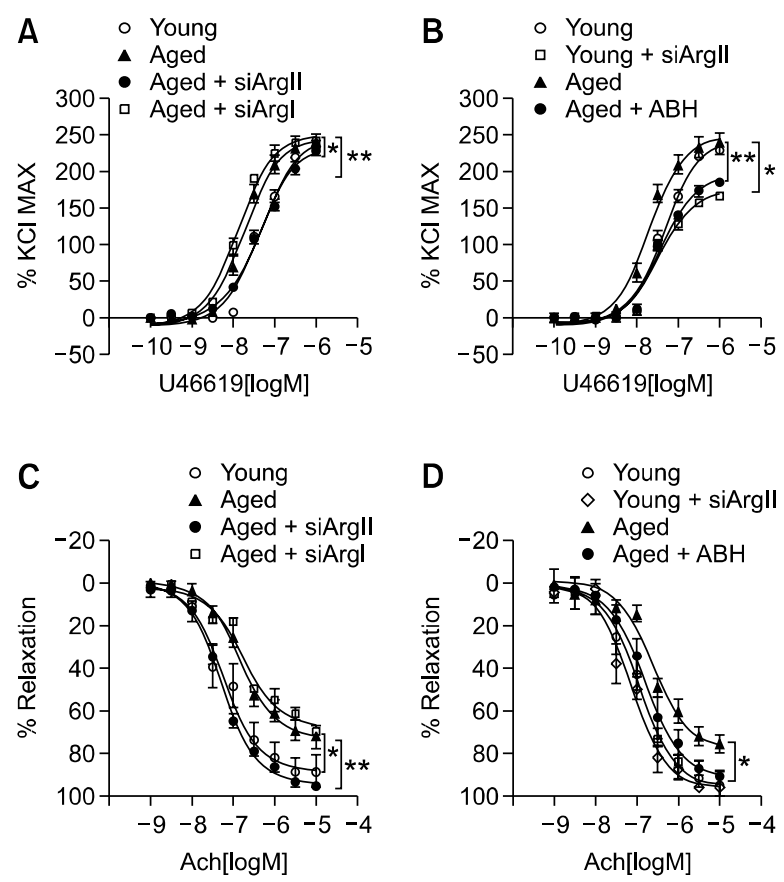

Figure 4. siArgll improved impaired vascular reactivity in aged mice. (A) Aged aortic vessels had augmented contractile responses to U46619 compared to young mice $\left(^{*}\right.$, young vs. aged, $\left.P<0.01\right)$. siArgll restored the U46619-mediated pressor response of aged aortic vessels to levels similar to that of young aortas $\left({ }^{*}\right.$, young vs. aged, $P<0.01$; ${ }^{* *}$, aged vs. aged + siArgll, $P<0.01)$. $n=4$ mice per each group. (B) siArgll attenuated contractile responses to $U 46619$ in young aorta $\left(^{*}\right.$, young vs. young + siArgll, $P<0.01)$ and $A B H$ incubation with old aorta significantly retarded U46619-dependent constriction (**, aged vs. aged $+\mathrm{ABH}, P<$ 0.01). (C) Endothelium-dependent relaxation responses to Ach were impaired in aged aortas ( ${ }^{*}$, young vs. aged, $P<0.01$ ). Impaired relaxation was recovered with siArgll pretreatment $\left({ }^{* *}\right.$, aged vs. aged + siArgll, $P$ $<0.05$ ). $n=4$ mice per each group. (D) $A B H$ incubation augmented Ach-dependent vessel relaxation in aged aorta $\left({ }^{*}\right.$, aged vs. aged $+\mathrm{ABH}$, $P<0.01)$.

nitroarginine methyl ester (L-NAME) treatment also decreased ROS production in aged mice ( ${ }^{\#}$ vs. aged, $0.32 \pm 0.06$ vs. $0.52 \pm 0.04$ change of DHE fluorescence/second, $P<0.01$ ). These data imply that increased eNOS uncoupling in aged mice leads to decreased NO production and increased ROS generation.

\section{siArgll restored impaired endothelial function in aged vasculature}

Because upregulated arginase activity increases ROS generation and decreases NO bioavailability, we determined whether Argll inhibition could attenuate this dysfunction. Vasoconstrictor responses to the agonist U46619 were markedly enhanced in aorta from aged mice, as manifested by a leftward shift in dose-response curves and reduced - $\log \mathrm{EC}_{50}$ values ${ }^{*}$, young vs. aged, $7.32 \pm 0.05 \mathrm{M}$ vs. $7.74 \pm 0.06$

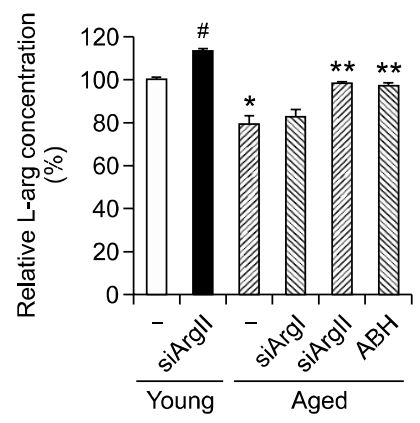

Figure 5. siArgll preincubation increased intracellular L-arg concentrations. Aortic vessels were incubated with or without siArgl, siArgll, and $\mathrm{ABH}$ and intracellular L-arg concentrations were measured with HPLC (see methods section). Treatment of siArgll to young vessels resulted in increase of L-arg amount ( ${ }^{\#}$ vs. young, $\left.P<0.01\right)$. The reduced L-arg level in aortas from aged mice was restored to that of young aortas by incubation of siArgll and $\mathrm{ABH}$ (* vs. young, $P<0.01$; ${ }^{* *}$ vs. aged, $P<0.01 ; n=6$ ).

$\mathrm{M}, P<0.01)$. $\mathrm{E}_{\max }$ was not significantly changed by this treatment (young vs. aged, $245.9 \pm 7.07 \%$ vs. $254.9 \pm 7.43 \%, \mathrm{~ns}$ ) (Figure 4A). However, incubation of aortic vessels from aged mice with siArgll increased $-\log \mathrm{EC}_{50}$ upto that observed in young $\left({ }^{* *}\right.$, aged vs. aged + siArgll, $7.74 \pm 0.06 \mathrm{M}$ vs. $7.32 \pm$ $0.04 \mathrm{M}, P<0.01)$. Consistent with siArgll incubation, arginase inhibition with $A B H$ in aged vessels attenuated vasoconstrictor responses to that of young aorta in both $\mathrm{E}_{\max }{ }^{* *}$, aged vs. aged $+\mathrm{ABH}$, $247.3 \pm 7.7 \%$ vs. $194.9 \pm 5.4 \%, P<0.01)$ and $-\log \mathrm{EC}_{50}(* *$, aged vs. aged $+\mathrm{ABH}, 7.70 \pm 0.07 \%$ vs. $7.41 \pm 0.05 \%, P<0.01)$ as shown in Figure 4B. On the other hand, siArgll incubation with young aortic vessels significantly decreased $\mathrm{E}_{\max }$ value $\left({ }^{*}\right.$, young vs. young + siArgll, $245.9 \pm 7.07 \%$ vs. 174.2 $\pm 6.43 \%, P<0.01$ ), but $-\log \mathrm{EC}_{50}$ was not changed (* young vs. young + siArgll, $7.32 \pm 0.05 \mathrm{M}$ vs. 7.35 $\pm 0.07 \mathrm{M}, \mathrm{NS}$ ). Next, to determine the effects of siRNA-mediated arginase inhibition on endotheliumdependent vasorelaxation, mouse aorta were preconstricted with U46619 $\left(10^{-8} \mathrm{M}\right)$, and doseresponse curves to the endothelium-dependent vasodilator acetylcholine (Ach) were constructed. The vasorelaxation responses in aged mice were significantly attenuated compared with those from young (Figure 4C, *, young vs. aged, $88.31 \pm$ $4.89 \%$ vs. $72.87 \pm 2.82 \%\left(E_{\max }\right), P<0.01 ; 7.23 \pm$ $0.13 \mathrm{M}$ vs. $\left.6.81 \pm 0.09 \mathrm{M}\left(-\log E C_{50}\right), P<0.01\right)$. Consistent with the above data, incubation of aged aorta with siArgll enhanced vasorelaxation responses (Figure $4 \mathrm{C},{ }^{* *}$, aged vs. aged + siArgll, $72.87 \pm$ $2.82 \%$ vs. $94.36 \pm 1.93 \%\left(E_{\max }\right), P<0.01 ; 6.81 \pm$ $0.09 \mathrm{M}$ vs. $\left.7.28 \pm 0.06 \mathrm{M}\left(-\log E \mathrm{C}_{50}\right), P<0.01\right)$. Also, inhibition of arginase activity with $A B H$ augmented vasorelaxation responses in both $E_{\max }$ (Figure 4D, *, aged vs. aged $+\mathrm{ABH}, 72.87 \pm 2.82 \%$ 
vs. $93.37 \pm 3.30 \%, P<0.01)$ and $-\log \mathrm{EC}_{50}\left({ }^{*}\right.$, aged vs. aged $+\mathrm{ABH}, 6.81 \pm 0.09 \mathrm{M}$ vs. $7.19 \pm 0.06 \mathrm{M}$, $P<0.01)$. On the other hand, incubation of young vessels with siArgll increased $-\log \mathrm{EC}_{50}$ value from $7.23 \pm 0.13 \mathrm{M}$ to $7.44 \pm 0.09 \mathrm{M}$ without effect on $E_{\max }$ (young vs. young + siArgll, $88.31 \pm 4.89 \%$ vs. $88.93 \pm 3.30 \%$, ns). However, the responses to the endothelium-independent vasodilator sodium nitroprusside (SNP) were not significantly changed in any group (data not shown).

\section{Argll inhibition increased L-arg bioavailability}

Given data suggesting that arginase reciprocally regulates NOS activity by limiting L-arg bioavailability, we used high-performance liquid chromatography (HPLC) to determine whether intracellular L-arg concentration was affected by altered arginase activity. L-arg content was significantly decreased in aged aorta but was recovered with siArgll and $\mathrm{ABH}$ incubation (Figure 5, * vs. young, $78.81 \pm$ $8.10 \%$ vs. $100 \pm 2.50 \%, P<0.01 ;{ }^{* *}$, siArgll vs. aged, $98.1 \pm 1.8 \%$ vs. $78.81 \pm 8.10 \%, P<0.01$; **, $\mathrm{ABH}$ vs. aged, $96.8 \pm 2.81$ vs. $78.81 \pm 8.10 \%$, $P<0.01)$. Furthermore, siArgll incubation with young aorta resulted in increase of the L-arg amount (\# vs. young, $113.0 \pm 3.1 \%$ vs. $100 \pm 2.50 \%, P<$ $0.05)$. These data suggest that aortic arginase activity play a key role in regulating intracellular L-arg concentration.

\section{Discussion}

The principal findings of this study were that Argll is the dominantly expressed arginase isoform in aortic vessels of aged mice, and specific inhibition of Argll with siRNA restores eNOS coupling, which is associated with increased NO production and decrease in ROS generation. Arginase inhibition augments U46619-induced vasoconstriction and endothelium-dependent vasorelaxation by increasing intracellular L-arg concentration in the vasculature of aged mice.

Previous publications have demonstrated that endothelial arginase constrains eNOS activity, thereby reducing NO bioavailability and contributing to vascular diseases, including aging (Berkowitz et al., 2003). In the present study, we show for the first time that increased Argll activity plays an important role in age-related vascular endothelial dysfunction without a change at the protein level. Argll expression has been well established in human (Ryoo et al., 2006) and mice (Lim et al., 2007) endothelial cells. Endothelial Argll activation and expression can be induced by a variety of vascular insults, including oxidized low-density lipoprotein (oxLDL), peroxynitrite, lipopolysaccharide, tumor necrosis factor- $\alpha$, interferon- $\gamma$, 8-bromo-cGMP, thrombin, and hypoxia (Abe and Berk, 1998; Morris et al., 1998; Chicoine et al., 2004; Nelin et al., 2007). oxLDL (Ryoo et al., 2011), thrombin (Ming et al., 2004), and peroxynitrite (Chandra et al., 2012) stimulate Argll activation via RhoA-dependent ROCK activation without a change in mRNA and protein levels. One study reported that peroxynitrite can react with the redox-active cysteine $\left(\mathrm{Cys}^{18}\right)$ of RhoA, which enhances GDP release from RhoA and thus modulates their activity (Brandes et al., 2005). Indeed, we found peroxynitrite formation as measured by the thiobarbituric acid reactive substances assay, was significantly increased in blood from aged mice (young vs. aged, $0.28 \pm 0.01$ vs. $0.33 \pm 0.01 \mu \mathrm{M}$ MDA, $P<0.05)$, which is consistent with a previous publication (van der Loo et al., 2000). Taken together, Argll upregulation in aged aorta may dependent on the increase of peroxynitrite formation and RhoA activation. Although Argl activity was upregulated by translational modification such as S-nitorsylation, Argll was not modified by such modification (data not shown). Therefore, further study needs to find a mechanism associated with Argll upregulation.

Vascular ROS production is enhanced in aged blood vessels (Abe and Berk, 1998; van der Loo et al., 2000; Ungvari et al., 2004; Brandes et al., 2005). There are four enzymatic systems that contribute to increased ROS production in various pathophysiological states: xanthine oxidase, NADPH oxidase, eNOS, and the mitochondrial electron transport chain (Cai and Harrison, 2000). Although eNOS normally produces the vasoprotectant molecule NO, it can also produce $\mathrm{O}_{2}^{-}$in the absence of either L-arginine or $\mathrm{BH}_{4}$. This phenomenon has been referred to as eNOS uncoupling (Stuehr et al., 2001; Landmesser et al., 2003). During aging, eNOS uncoupling plays a key role in increased ROS production. Our data that increased ROS production in the endothelium of aging mice was prevented with preincubation of the eNOS inhibitor L-NAME is consistent with previous observations (Kim et al., 2009). Furthermore, the ratio of eNOS dimer to monomer in aged mice was significantly decreased compared with that in young. Together, these data suggest that eNOS uncoupling is an important contributor to age-related endothelial dysfunction.

Increased expression of eNOS may depend on shear stress and hemodynamic forces (Sessa et al., 1994; Ranjan et al., 1995) because of the presence of a shear stress-responsive element in the promoter region of the eNOS gene (Nishida et al., 1992). Consistent with the demonstration, eNOS 
expression was increased in aorta (Cernadas et al., 1998; van der Loo et al., 2000) and not changed in artery (Yang et al., 2009) and decreased in arteriole (Csiszar et al., 2002). Furthermore, increased expression of eNOS protein in aged aorta may be one of the compensatory mechanisms to counterbalance endothelial dysfunction by increased arginase activity.

There are a number of potential reasons why eNOS might be uncoupled and lead to increased ROS production in aging (Stuehr et al., 2001). Oxidative stress may damage and deplete $\mathrm{BH}_{4}$ and contribute to eNOS uncoupling (Milstien et al., 1999). Limited L-arg bioavailability also promotes eNOS uncoupling (Boger et al., 1995). Consistent with this concept, increased Argll activity was associated with decreased intracellular L-arg and Argll inhibition restored L-arg concentration in aortic vessels (Figure 5 ). We found that $L$-arg concentration was $66.6 \mu \mathrm{mol} / \mathrm{mg}$ protein in young mice and 51.9 $\mu \mathrm{mol} / \mathrm{mg}$ proteins in aged. Closs and colleagues (Closs et al., 2000; Simon et al., 2003) have demonstrated that endothelial cells contain two pools of L-arg. Pool I is regulated by the cationic transporter and can be depleted by cationic amino acid L-lysine and pool II, which is further subdivided into IIA and IIB, is accessible to eNOS but is not freely exchangeable with extracellular L-lysine or L-arg. Mitochondrial Argll utilizes pool IIB, which might be influenced by arginase and could modulate the local concentration of L-arg available to eNOS. Although our study did not distinguish among the L-arg pools, we demonstrated that arginase activity is involved in regulating intracellular $L$-arg concentration. This relationship between arginase activity and L-arg concentration was previously described in mouse plasma (Erdely et al., 2010).

In summary, we demonstrated that Argll is upregulated in aortic vessels of aged mice and plays a role in regulating NO production through eNOS uncoupling. Incubation with siArgll inhibits arginase activity, enhances NO generation, attenuates ROS production, and improves endothelial function by augmenting eNOS coupling via increased bioavailability of L-arg. Thus Argll may be valuable target in age-related vascular diseases.

\section{Methods}

\section{Materials}

MnTBAP (Mn (III)tetrakis (4-benzoic acid) porphyrin Chloride) and L-NAME ( $\mathrm{N}^{\mathrm{G}}$-nitro-L-arginine methyl ester), were obtained from Calbiochem. All other reagents were purchased from Sigma unless otherwise stated.

\section{Animals}

Young (10 \pm 3 weeks) and aged (45 \pm 5 weeks) mice (C57BL/6J) were used for all experiments. Mice were housed at $23^{\circ} \mathrm{C}$ under a 12 -h light $/ 12-\mathrm{h}$ dark cycle. The dark period was from 10:00 to 22:00. All animals had access ad libitum to water and food (Nara Biotech.). The study protocols were in accordance with the Guide for the Care and Use of Laboratory Animals (Institutional Review Board, Kangwon National University).

\section{SiRNA incubation}

Thoracic aortas were dissected from euthanized mice, cut into 1.5-mm rings, and incubated overnight in Dulbecco's modified Eagle's medium (DMEM) containing siArgl and/or siArgll (100 nM each, Santa Cruz Biotechnology, sc-29727 and Sc-29730, respectively).

\section{RT-PCR}

Total RNA from aortic vessels was prepared with TRIzol reagent according to the manufacturer's protocol (Gibco). RT-PCR was performed as described previously (Ryoo et al., $2006{ }^{\# 13) . ~ P C R-p r i m e r ~ s e q u e n c e s ~ o f ~ A r g l, ~ A r g l l, ~ a n d ~}$ GAPDH (Bioneer) are as follows: Argl forward 5'-gga aga gac ctt cag cta cct gct gg-3', reverse 5'-ccc agt tca cag tac tct tca cc-3', 251-bp PCR-product; Argll forward 5'-ggc aga ggc caa tcc acc tga gtt ttg- $3^{\prime}$, reverse $5^{\prime}$-ctg acc aaa act tga agc aat cac atc c-3', 251-bp PCR product; GAPDH forward $5^{\prime}$-agg ccg gtg ctg agt atg tc-3', reverse 5'-tgc ctg ctt cac cac ctt ct-3', 530-bp PCR-product.

\section{Arginase activity assay}

Aortic lysates were prepared by homogenization in lysis buffer $(50 \mathrm{mM}$ Tris- $\mathrm{HCl}, \quad \mathrm{pH} 7.5,0.1 \mathrm{mM}$ ethylenediaminetetraacetic acid [EDTA] and protease inhibitors) at $4^{\circ} \mathrm{C}$ followed by centrifugation for $20 \mathrm{~min}$ at $14,000 \times \mathrm{g}$ at $4^{\circ} \mathrm{C}$. The supernatants were used to assay arginase activity as previously described (Ryoo et al., 2006).

\section{Western blotting and eNOS dimerization analysis}

Aortic segments were homogenized in the buffer $(50 \mathrm{mM}$ Tris-HCl, $150 \mathrm{mM} \mathrm{NaCl}, 1 \%$ Nonidet P-40, 1 mM EDTA, 1 $\mu \mathrm{g} / \mathrm{ml}$ leupeptin, $1 \mu \mathrm{g} / \mathrm{ml}$ pepstatin, $1 \mu \mathrm{g} / \mathrm{ml}$ aprotinin, $1 \mathrm{mM}$ phenylmethylsulfonylflouride, $1 \mathrm{mM}$ sodium orthovanadate, and $1 \mathrm{mM}$ sodium fluoride) and centrifuged for $30 \mathrm{~min}$ at $14,000 \times g$. Supernatant protein concentrations were analyzed by the Bradford method. Protein samples $(100 \mu \mathrm{g})$ were separated using sodium dodecyl sulfate polyacrylamide gel electrophoresis (10\% gels) and transferred to nitrocellulose membranes (Bio-Rad). The blots were incubated with primary antibodies: monoclonal anti-Argl (Santa Cruz Biotechnology), anti-Argll (Santa Cruz Biotechnology), anti-eNOS (BD Biosciences), or anti- $\beta$-tubulin (BD Biosciences) antibodies, followed by an appropriate secondary antibody (Amersham). The signals were detected using an enhanced chemiluminescence detection reagent and X-ray films. eNOS dimers and monomers were separated using low-temperature SDS-PAGE as previously described (Woo et al., 2010). 


\section{Estimation of NO or ROS generation using DAF-FM or DHE in isolated mice aorta}

Mice aortic rings were isolated and incubated overnight at $37^{\circ} \mathrm{C}$ under $5 \% \mathrm{CO}_{2}$ in DMEM containing $2 \%$ fetal bovine serum and antibiotics $(1 \times)$ in the presence or absence of siRNA (Ryoo et al., 2006). The fluorescence from the aortic endothelium was measured at different time intervals under microscopy (Woo et al., 2010).

\section{Aortic vascular tension assay}

Mice were anesthetized using isoflurane, and their thoracic aortas were rapidly removed, placed on ice-caged oxygenated Krebs-Ringer bicarbonate solution (in $\mathrm{mM}$ : $\mathrm{NaCl} 118.3, \mathrm{KCl} 4.7, \mathrm{MgSO}_{4} 1.2, \mathrm{KH}_{2} \mathrm{PO}_{4}$ 1.2, $\mathrm{CaCl}_{2}$ 1.6, $\mathrm{NaHCO}_{3} 25$, glucose 11.1), and cleared of adherent connective tissues. Individual mouse aortas were cut into 2.5- $\mathrm{mm}$ rings and suspended between two wire stirrups $(150 \mu \mathrm{m})$ in a myograph (Multi myograph system DMT-620) in $10 \mathrm{ml} \mathrm{Krebs-ringer}\left(95 \% \mathrm{O}_{2}-5 \% \mathrm{CO}_{2}, \mathrm{pH} 7.4,37^{\circ} \mathrm{C}\right)$. One stirrup was connected to a three-dimensional micromanipulator, and the other was attached to a force transducer. The rings were passively stretched at 10-min intervals in increments of $200 \mathrm{mg}$ to reach optimal tone $(600 \mathrm{mg}$ ). After the arterial rings had been stretched to their optimal resting tone, the contractile response to 100 $\mathrm{mM} \mathrm{KCl}$ was determined. The response to a maximal dose of $\mathrm{KCl}$ was used to normalize the responses to agonist across vessel rings. Dose responses to the vasoconstrictor U46619 $\left(10^{-10}-10^{-6} \mathrm{M}\right)$ were performed, followed by responses to the vasodilators acetylcholine (Ach, $10^{-9}-10^{-5}$ $\mathrm{M})$ and sodium nitroprusside (SNP, $10^{-9}-10^{-5} \mathrm{M}$ ) were performed after preconstriction with U46619 $\left(10^{-8} \mathrm{M}\right)$. At the end of the experiments, NO-dependent vasorelaxation activity was confirmed by adding the guanylate cyclase inhibitor ODQ $(1 \mathrm{H}-[1,2,4]$ oxadizolo[4,3-a]quinoxalin-1-one, $\left.10^{-6} \mathrm{M}\right)$. Data were collected online using a MacLab system and analyzed using Dose Response Software (AD Instruments).

\section{Determination of intracellular L-arginine concentrations}

Intracellular L-arg concentration was determined by HPLC using pre-column derivatization with o-phthalaldehyde (OPA) according to a modified version of a previously published method (Boger et al., 1995). L-arginine $(100 \mu \mathrm{mol} / \mathrm{L})$ was added to cell lysate $(0.5 \mathrm{ml})$ as an internal standard. The samples were extracted on solid-phase extraction cartridges (CBA Bond Elut, Varian). Recovery rates were $87.5 \pm$ $3.9 \%$. Eluates were dried over nitrogen and resuspended in double-distilled water for HPLC analysis. HPLC was performed on a computer-controlled Waters chromatography system (M600E) consisting of an automatic injector (M7725i, Waters Co.) and a fluorescence detector (FP-1520, JASCO) in the Central Laboratory of Kangwon National University. Samples were incubated for exactly $1 \mathrm{~min}$ with OPA reagent $(5.4 \mathrm{mg} / \mathrm{ml}$ OPA in borate buffer, $\mathrm{pH} 8.4$, containing $0.4 \%$ 2-mercaptoethanol) before automatic injection into the HPLC. The OPA derivative of L-arginine was separated on a $150 \times 4.6 \mathrm{~mm}-3.5 \mu \mathrm{m}$ Zorbax Eclipse XDB-C18 column with the fluorescence detector set at $340 \mathrm{~nm}$ (excitation) and $450 \mathrm{~nm}$ (emission). Samples were eluted from the column with $0.96 \%$ citric acid/methanol (70:30), $\mathrm{pH} 6.8$, at a flow rate of $1.5 \mathrm{ml} / \mathrm{min}$.

\section{Statistics}

All data are represented as mean \pm standard deviation of at least four independent experiments. Unpaired Student's $t$-tests were used to determine significant differences. A value of $P<0.05$ was accepted as significant.

\section{Acknowledgements}

This work was supported by the Basic Science Research Program of the National Research Foundation of Korea (NRF) funded by the Ministry of Education, Science, and Technology (2011-0026173).

\section{References}

Abe J, Berk BC. Reactive oxygen species as mediators of signal transduction in cardiovascular disease. Trends Cardiovasc Med 1998;8:59-64

Adler A, Messina E, Sherman B, Wang Z, Huang H, Linke A, Hintze TH. NAD(P)H oxidase-generated superoxide anion accounts for reduced control of myocardial $\mathrm{O} 2$ consumption by NO in old Fischer 344 rats. Am J Physiol Heart Circ Physiol 2003;285:H1015-22

Berkowitz DE, White R, Li D, Minhas KM, Cernetich A, Kim S, Burke S, Shoukas AA, Nyhan D, Champion HC, Hare JM. Arginase reciprocally regulates nitric oxide synthase activity and contributes to endothelial dysfunction in aging blood vessels. Circulation 2003;108:2000-6

Bivalacqua TJ, Burnett AL, Hellstrom WJ, Champion HC. Overexpression of arginase in the aged mouse penis impairs erectile function and decreases eNOS activity: influence of in vivo gene therapy of anti-arginase. Am J Physiol Heart Circ Physiol 2007;292:H1340-51

Boger RH, Bode-Boger SM, Mugge A, Kienke S, Brandes R, Dwenger A, Frolich JC. Supplementation of hypercholesterolaemic rabbits with L-arginine reduces the vascular release of superoxide anions and restores NO production. Atherosclerosis 1995; 117:273-84

Brandes RP, Fleming I, Busse R. Endothelial aging. Cardiovasc Res 2005;66:286-94

Cai H, Harrison DG. Endothelial dysfunction in cardiovascular diseases: the role of oxidant stress. Circ Res 2000;87:840-4

Cernadas MR, Sanchez de Miguel L, Garcia-Duran M, Gonzalez-Fernandez F, Millas I, Monton M, Rodrigo J, Rico L, Fernandez P, de Frutos T, Rodriguez-Feo JA, Guerra J, Caramelo C, Casado S, Lopez F. Expression of constitutive and inducible nitric oxide synthases in the vascular wall of young and aging rats. Circ Res 1998;83:279-86

Chandra S, Romero MJ, Shatanawi A, Alkilany AM, Caldwell 
RB, Caldwell RW. Oxidative species increase arginase activity in endothelial cells through the RhoA/Rho kinase pathway. Br J Pharmacol 2012;165:506-19

Chicoine LG, Paffett ML, Young TL, Nelin LD. Arginase inhibition increases nitric oxide production in bovine pulmonary arterial endothelial cells. Am J Physiol Lung Cell Mol Physiol 2004;287:L60-8

Closs EI, Scheld JS, Sharafi M, Forstermann U. Substrate supply for nitric-oxide synthase in macrophages and endothelial cells: role of cationic amino acid transporters. Mol Pharmacol 2000;57:68-74

Csiszar A, Ungvari Z, Edwards JG, Kaminski P, Wolin MS, Koller A, Kaley G. Aging-induced phenotypic changes and oxidative stress impair coronary arteriolar function. Circ Res 2002;90:1159-66

Csiszar A, Wang M, Lakatta EG, Ungvari Z. Inflammation and endothelial dysfunction during aging: role of NF-kappaB. J Appl Physiol 2008;105:1333-41

Erdely A, Kepka-Lenhart D, Salmen-Muniz R, Chapman R, Hulderman T, Kashon M, Simeonova PP, Morris SM, Jr. Arginase activities and global arginine bioavailability in wild-type and ApoE-deficient mice: responses to high fat and high cholesterol diets. PloS one 2010;5:e15253.

Finkel T, Holbrook NJ. Oxidants, oxidative stress and the biology of ageing. Nature 2000;408:239-47

Haraguchi Y, Takiguchi M, Amaya Y, Kawamoto S, Matsuda I, Mori M. Molecular cloning and nucleotide sequence of cDNA for human liver arginase. Proc Natl Acad Sci USA $1987 ; 84: 412-5$

Heo J, Campbell SL. Mechanism of redox-mediated guanine nucleotide exchange on redox-active Rho GTPases. J Biol Chem 2005;280:31003-10

Holowatz LA, Kenney WL. Up-regulation of arginase activity contributes to attenuated reflex cutaneous vasodilatation in hypertensive humans. J Physiol 2007;581:863-72

Kim JH, Bugaj LJ, Oh YJ, Bivalacqua TJ, Ryoo S, Soucy KG, Santhanam L, Webb A, Camara A, Sikka G, Nyhan D, Shoukas AA, llies M, Christianson DW, Champion HC, Berkowitz DE. Arginase inhibition restores NOS coupling and reverses endothelial dysfunction and vascular stiffness in old rats. J Appl Physiol 2009;107:1249-57

Landmesser U, Dikalov S, Price SR, McCann L, Fukai T, Holland SM, Mitch WE, Harrison DG. Oxidation of tetrahydrobiopterin leads to uncoupling of endothelial cell nitric oxide synthase in hypertension. J Clin Invest 2003;111: 1201-9

Lim HK, Lim HK, Ryoo S, Benjo A, Shuleri K, Miriel V, Baraban E, Camara A, Soucy K, Nyhan D, Shoukas A, Berkowitz DE. Mitochondrial arginase II constrains endothelial NOS-3 activity. Am J Physiol Heart Circ Physiol 2007;293:H3317-24

Meaume S, Benetos A, Henry OF, Rudnichi A, Safar ME. Aortic pulse wave velocity predicts cardiovascular mortality in subjects $>70$ years of age. Arterioscler Thromb Vasc Biol 2001;21:2046-50

Meurs $\mathrm{H}$, Maarsingh $\mathrm{H}$, Zaagsma J. Arginase and asthma: novel insights into nitric oxide homeostasis and airway hyperresponsiveness. Trends Pharmacol Sci 2003;24:450-5

Milstien S, Katusic Z. Oxidation of tetrahydrobiopterin by peroxynitrite: implications for vascular endothelial function. Biochem Biophys Res Commun 1999;263:681-4

Ming XF, Barandier C, Viswambharan H, Kwak BR, Mach F, Mazzolai L, Hayoz D, Ruffieux J, Rusconi S, Montani JP, Yang Z. Thrombin stimulates human endothelial arginase enzymatic activity via RhoA/ROCK pathway: implications for atherosclerotic endothelial dysfunction. Circulation 2004; 110:3708-14

Morris SM Jr, Bhamidipati D, Kepka-Lenhart D. Human type Il arginase: sequence analysis and tissue-specific expression. Gene 1997; 193:157-61

Morris SM Jr, Kepka-Lenhart D, Chen LC. Differential regulation of arginases and inducible nitric oxide synthase in murine macrophage cells. Am J Physiol 1998;275:E740-7

Nelin LD, Wang X, Zhao Q, Chicoine LG, Young TL, Hatch DM, English BK, Liu Y. MKP-1 switches arginine metabolism from nitric oxide synthase to arginase following endotoxin challenge. Am J Physiol Cell Physiol 2007;293:C632-40

Nishida K, Harrison DG, Navas JP, Fisher AA, Dockery SP, Uematsu M, Nerem RM, Alexander RW, Murphy TJ. Molecular cloning and characterization of the constitutive bovine aortic endothelial cell nitric oxide synthase. J Clin Invest 1992;90:2092-6

Que LG, Kantrow SP, Jenkinson CP, Piantadosi CA, Huang $Y C$. Induction of arginase isoforms in the lung during hyperoxia. Am J Physiol 1998;275:L96-102

Ranjan V, Xiao Z, Diamond SL. Constitutive NOS expression in cultured endothelial cells is elevated by fluid shear stress. Am J Physiol 1995;269:H550-5

Ryoo S, Lemmon CA, Soucy KG, Gupta G, White AR, Nyhan $D$, Shoukas A, Romer LH, Berkowitz DE. Oxidized low-density lipoprotein-dependent endothelial arginase II activation contributes to impaired nitric oxide signaling. Circ Res 2006;99:951-60

Ryoo S, Bhunia A, Chang F, Shoukas A, Berkowitz DE, Romer LH. OxLDL-dependent activation of arginase II is dependent on the LOX-1 receptor and downstream RhoA signaling. Atherosclerosis 2011;214:279-87

Santhanam L, Christianson DW, Nyhan D, Berkowitz DE. Arginase and vascular aging. J Appl Physiol 2008;105: 1632-42

Sessa WC, Pritchard K, Seyedi N, Wang J, Hintze TH. Chronic exercise in dogs increases coronary vascular nitric oxide production and endothelial cell nitric oxide synthase gene expression. Circ Res 1994;74:349-53

Simon A, Plies L, Habermeier A, Martine U, Reining M, Closs El. Role of neutral amino acid transport and protein breakdown for substrate supply of nitric oxide synthase in human endothelial cells. Circ Res 2003;93:813-20

Steppan J, Ryoo S, Schuleri KH, Gregg C, Hasan RK, White AR, Bugaj LJ, Khan M, Santhanam L, Nyhan D, Shoukas AA, Hare JM, Berkowitz DE. Arginase modulates myocardial contractility by a nitric oxide synthase 1-dependent mechanism. Proc Natl Acad Sci USA 2006;103:4759-64 
Stuehr D, Pou S, Rosen GM. Oxygen reduction by nitricoxide synthases. J Biol Chem 2001;276:14533-6

Ungvari Z, Csiszar A, Kaley G. Vascular inflammation in aging. Herz 2004;29:733-40

van der Loo B, Labugger R, Skepper JN, Bachschmid M, Kilo $\mathrm{J}$, Powell JM, Palacios-Callender M, Erusalimsky JD, Quaschning T, Malinski T, Gygi D, Ullrich V, Luscher TF. Enhanced peroxynitrite formation is associated with vascular aging. J Exp Med 2000;192:1731-44

White AR, Ryoo S, Li D, Champion HC, Steppan J, Wang D,
Nyhan D, Shoukas AA, Hare JM, Berkowitz DE. Knockdown of arginase I restores NO signaling in the vasculature of old rats. Hypertension 2006;47:245-51

Woo A, Min B, Ryoo S. Piceatannol-3'-O-beta-Dglucopyranoside as an active component of rhubarb activates endothelial nitric oxide synthase through inhibition of arginase activity. Exp Mol Med 2010;42:524-32

Yang YM, Huang A, Kaley G, Sun D. eNOS uncoupling and endothelial dysfunction in aged vessels. Am J Physiol 2009;297:H1829-36 